\title{
The Effect of Aluminum and Ammonium Perchlorate Content on Temperature Sensitivity, Mechanical Properties and Performance of HTPB Propellants
}

\author{
By F. Nihal TüzüN \\ Engineering Faculty of Hitit University, Department of Chemical Engineering, 19030, Çorum, Turkey
}

(Received August 16th, 2006)

\begin{abstract}
This paper describes the effect of aluminum content variation of HTPB (hydroxyl terminated polybutadiene) propellants on temperature sensitivity, mechanical properties and performance values. Aluminum (Al) content was applied as 16,18 and 20 percent to the propellant compositions and those compositions were tested at small test motors with three different propellant area ratios $(K=200,250$ and 300) by keeping the propellant grain at three different temperatures (231, 258 and $323 \mathrm{~K})$. As a result of this, a relationship such as $P=a e^{s T}$ was determined with different coefficients for each of the three compositions and propellant area ratios. The lowest temperature sensitivity value was obtained for the composition containing $20 \% \mathrm{Al}$ and $65 \% \mathrm{AP}$. The second relation as $P=b K^{y}$ was derived for three propellants and temperatures. The highest pressure was found with the $K$ value of 300 for the propellant including $16 \% \mathrm{Al}$ and $69 \%$ $\mathrm{AP}$ at $323 \mathrm{~K}$. The third relationship such as $r=c P^{n}$ was also determined for three propellant compositions and temperatures. It was observed that the propellant having 16\% $\mathrm{Al}$ and $69 \% \mathrm{AP}$ had the highest burning rate at $323 \mathrm{~K}$. The highest maximum tensile stress and elongation values were obtained for the propellants including $20 \% \mathrm{Al}$ and $16 \% \mathrm{Al}$ respectively. Evaluation of performance values for those propellants exhibits that the maximum characteristic velocity value is attained for the propellant containing $16 \% \mathrm{Al}$ and $69 \% \mathrm{AP}$.
\end{abstract}

Key Words: Aluminum, Temperature Sensitivity, Mechanical Properties, Characteristic Velocity

\section{Nomenclature}

\begin{aligned} & $\mathrm{Al}:$ aluminum \\ & $\mathrm{AP}:$ ammonium perchlorate \\ &$P:$ pressure \\ &$T:$ temperature \\ &$a:$ constant in Eq. $(6) \\ & s:$ temperature sensitivity \\ &$\Pi_{\mathrm{Pc}}:$ percentage variation of combustion pressure temper- \\ & ature sensitivity \\ &$T_{\mathrm{p}}:$ initial propellant temperature \\ &$P_{\mathrm{c}}:$ combustion pressure \\ &$K:$ propellant-area ratio \\ &$y: K$ index \\ &$b:$ constant in Eq. $(7) \\ & r:$ burning rate \\ &$c:$ burning rate constant \\ &$n:$ combustion index \\ &$C^{*}:$ characteristic velocity \\ &$A_{\mathrm{t}}:$ nozzle throat area \\ & \hline$P \mathrm{~d} t:$ area under the $P-t$ curve \\ &$W:$ weight of the propellant \\ &$\dot{m}:$ propellant consumption or mass flow rate of the pro- \\ &$\gamma:$ pellant \\ &$R:$ gatio of specific heats \\ &$T_{\mathrm{c}}:$ combustion temperature \\ &$l:$ density of gas \\ &$M_{\mathrm{w}}:$ mean molecular weight of combustion products \\ &\end{aligned}

(C) 2007 The Japan Society for Aeronautical and Space Sciences

\section{Introduction}

Modern solid composite propellants are heterogeneous and consist of three basic components: an organic polymer which serves as both a binder and combustible fuel, a solid oxidizer which may contribute to gas formation and a metallic fuel which gives energy to the propellant. ${ }^{1)}$

Temperature sensitivity, mechanical properties and performance parameters are very important in the evaluation of the rocket propellants.

Temperature sensitivity is known as the effect of the propellant temperature to the performance of the solid propellant rocket motors. Equilibrium combustion pressure is affected by the temperature of the propellant grain before ignition for the propellant area ratio $(K)$ given. Low temperature sensitivity values increase the performance and decrease the cost of rocket systems. The designer must give a guarantee for safety limits so that the motor components can compensate with the pressure changes during the operation. As temperature sensitivity values increase, variations in the operating pressure also increase. When the temperature sensitivities of motors increase, the weight of the mechanical components of the motors must also increase. Repeatability of propellant performance results and better tolerance values in pressure changes make the usage of the lower cost mechanical components of motors possible. ${ }^{2)}$

The temperature sensitivity of a rocket motor for a constant propellant area ratio $(K)$ is usually expressed as the percent change of the considered variable (e.g. pressure) per degree Kelvin. ${ }^{3)}$ 


$$
\Pi P_{\mathrm{c}}=\frac{1}{P_{c}}\left(\frac{\partial P_{\mathrm{c}}}{\partial T_{\mathrm{p}}}\right)_{K}
$$

The effect of temperature sensitivity should be considered in the design of solid propellant rocket motors. This is, because, temperature sensitivity directly affects the design of the rocket motor case and also the selection of the minimum safely applicable value of the propellant area ratio $(K)$. The best propellant area ratio must be selected for these mechanical components; so, combustion pressure will be above the minimum combustion limit at the lowest propellant temperature. ${ }^{3)}$

Mechanical properties consist of maximum tensile stress, elongation at maximum tensile stress and elastic modulus. A strain in the propellant has three principal independent causes. First, a strain within the bonded propellant grain can be induced by propellant shrinkage during cure. In current practice, the cure reaction is carried out under conditions resulting in essentially no strain in the grain at ambient temperature. The optimum mechanical properties of the elastomeric binder in the propellant must be obtained by forming the least number of chemical bonds so as to insure minimum shrinkage of the propellant during cure. ${ }^{4)}$

The second and most important cause of a strain is the difference in thermal expansion between the chamber, the insulating material and the propellant bonded together in the motor. Since thermal expansion coefficient of composite propellant is approximately ten times greater than a steel motor case. ${ }^{5)}$ The environmental temperature, except for very large motors, is usually not controlled. It is not unusual to test and to expect the motor to operate over a temperature range of 213 to $355 \mathrm{~K}$. If the propellant loses its elastomeric properties at low temperature, it will become brittle and may fracture because of induced tensional strain resulting from differences in thermal contraction or because of the sudden compressive strains produced by rapid pressurization of the motor. ${ }^{4)}$

Another cause of a strain is produced in a case bonded grain by motor ignition. During the ignition period, the pressure in the motor chamber increases rapidly to its equilibrium or operating value usually is among 1.38 and $6.89 \mathrm{~N} /$ $\mathrm{mm}^{2}$ depending upon motor design. This pressurization also produces strains in the grain. ${ }^{5)}$

The performance of the propellant is directly proportional to the enthalpy release of the oxidizer and fuel ingredients as they undergo combustion, and inversely proportional to the molecular weight of the gases produced in the combustion reaction. Aluminum used as a fuel has combustion products which are relatively high in molecular weight and are in most cases, not gases at all, but solids. However, the enthalpy release by the combustion of aluminum is so great. Another material affecting the performance is the ammonium perchlorate used as an oxidizer. This material has a high negative enthalpy of formation, limiting its energy release upon combustion, and in addition, it produces hydrogen chloride, a relatively high molecular-weight toxic gas. ${ }^{6}$ )

There are some important performance parameters. One of these is the characteristic velocity. The characteristic velocity $\left(C^{*}\right)$ depends only slightly on the chamber pressure and is otherwise independent of the design of the rocket. It can be expressed as a function of the combustion gas properties and is therefore, a criterion of propellant performance.

Advantages of expressing the performance in terms of characteristic velocity is that it can be computed from the values of $P_{\mathrm{c}}, A_{\mathrm{t}}$ and $W$, all of which can be experimentally determined with a high degree of accuracy ${ }^{7)}$ and it is defined as follows:

$$
C^{*}=\frac{A_{t} \int P \mathrm{~d} t}{W}
$$

Another way of expressing the characteristic velocity can be given, as below,

$$
C^{*}=\frac{P_{c} A_{t}}{\dot{m}}
$$

and it can also be expressed by means of specific heats,

$$
C^{*}=\frac{\sqrt{\gamma R T_{\mathrm{c}}}}{\gamma \sqrt{\left(\frac{2}{\gamma+1}\right)^{\frac{(\gamma+1)}{(\gamma-1)}}}}
$$

or it can be defined as a function of

$$
C^{*}=\sqrt{\frac{\gamma P}{\ell}}=\sqrt{\frac{\gamma R T_{c}}{M_{\mathrm{w}}}}
$$

\section{Experimental}

In those experiments, propellants were prepared with a solid content of $85.5 \%$ by weight and kept as constant in all compositions. The amount of iron (III) oxide (Merck) and IPDI (isophorone diisocyanate) was also kept as constant at $0.5 \%$ without considering small variation required in $\mathrm{Fe}_{2} \mathrm{O}_{3}$ content due to AP pyrolysis rate and $0.796 \%$ respectively. The particle size distribution of AP was bimodal and consists of coarse and fine particles. The coarse and fine particle sizes were 200 and 5-7 $\mu \mathrm{m}$ respectively. In addition, the mass ratio of coarse and fine AP was 70/30. The aluminum used was available as irregular shaped particles having $8-10 \mu \mathrm{m}$ in mean particle size.

The aluminum $(\mathrm{Al})$ content of the propellants was increased to 16,18 and 20 percent and accordingly the oxidizer ammonium perchlorate (AP) content was decreased at equal amounts. Propellants were prepared by mixing AP, binder, $\mathrm{Al}$ and the other additives in a sigma blade vertical mixer with the capacity of $18.922 \mathrm{dm}^{3}$. After three hours passed for mixing, addition of curing agent IPDI was made in the last 15 minutes before the completion of the mixing time. The propellant which has a center perforate grain with end burning to produce a neutral pressure trace was poured into the steel cases of $70 \mathrm{~mm}$ in diameter and $125 \mathrm{~mm}$ in length. It was cured at $338 \mathrm{~K}$ for seven days, then, the propellant was placed into the small test motors and kept at three different $(231,258$ and $323 \mathrm{~K})$ temperatures for a night. Then, they were subjected to tests with three different 
nozzle diameters $(8.38,9.17$ and $10.25 \mathrm{~mm})$ and area ratios (200, 250 and 300) statically. Also, three small motors were ignited for each $K$ value during the experiments. Three different parameters were attained by varying Al content, nozzle diameter and propellant grain temperature. In the experiments, one of the parameters was changed and the others were kept as constant. A specific relationship was determined for each of the compositions from those parameters.

In addition to this, mechanical properties consisting of elongation at maximum tensile stress, maximum tensile stress and elastic modulus of the propellants were obtained at $50 \mathrm{~mm} / \mathrm{min}$ crosshead speed by using INSTRON tester according to the JANAF standard procedure. ${ }^{8)}$ Mechanical properties were measured at five different temperatures as 233 K, 248 K, 296 K, 308 K and 323 K. Propellant samples were placed into the jaws of the instrument and then, they were tested until the break point. Five samples were tested for each propellant composition.

\section{Results and Discussion}

The $\mathrm{Al}$ content of the propellants prepared changed from 16 to 18 and then to 20 percent when the oxidizer ammonium perchlorate (AP) content was decreased at equal amounts. The reason for the selection of aluminum content among 16-20\% can be expressed in terms of the investigation made before. ${ }^{9)}$ In this study, the Al content was increased from 0 to $20 \%$, while AP content was decreased at the same amount. Although, mechanical properties of the propellants were improving below $16 \% \mathrm{Al}$, ballistic properties deteriorated. For this reason, a suitable interval for the propellant used in short and medium range artillery rockets was determined between 16 and 20\% Al.

After keeping small test motors at three different temperatures $(231,258$ and $323 \mathrm{~K})$ for a night, they were tested by using three different nozzle diameters (8.38, 9.17 and $10.25 \mathrm{~mm}$ ) and area ratios (200, 250 and 300). Al content, nozzle diameter and propellant grain temperature were evaluated as three different parameters. A specific relation was determined for each composition by varying one of the parameters and keeping the others as constant. The relationship derived is given below in the form of:

$$
P=a e^{s T}
$$

The relationships explaining the variation of average pressure with temperature are given in Table 1 for three compositions and three different $K$ values.

As a consequence of the evaluation in Table 1, pressure increases with $K$ value and temperature, whereas, temperature sensitivity $(s)$ decreases and $(a)$ increases with increasing the $\mathrm{Al}$ and decreasing the $\mathrm{AP}$ content. However, maximum $(s)$ values were attained at 16 and $18 \% \mathrm{Al}$ in the $K$ values of 200, 250 and 300 respectively due to the effect of higher $\mathrm{Al}$ content and higher $K$ values for the same temperature range.

\subsection{Temperature sensitivity}

Temperature sensitivity increases with increasing the $\mathrm{Al}$
Table 1. Variation of average pressures obtained from $P-t$ graphs with propellant grain temperature for three different propellant compositions in terms of the coarse/fine AP ratio of 70/30 and $K$ values.

\begin{tabular}{cccc}
\hline $\begin{array}{c}\text { Aluminum } \\
(\%)\end{array}$ & $\begin{array}{c}K \\
\text { (Propellant area ratio) }\end{array}$ & $\begin{array}{c}\ln P_{\mathrm{av}} \\
(\mathrm{MPa})\end{array}$ & $P=a e^{s T}(\mathrm{MPa})$ \\
\hline 16 & 200 & 1.564 & $P=2.9046 e^{0.00184 \mathrm{~T}}$ \\
16 & 250 & 1.926 & $P=4.3332 e^{0.00170 \mathrm{~T}}$ \\
16 & 300 & 2.179 & $P=6.2227 e^{0.00130 \mathrm{~T}}$ \\
18 & 200 & 1.510 & $P=3.0676 e^{0.00144 \mathrm{~T}}$ \\
18 & 250 & 1.831 & $P=3.6255 e^{0.00201 \mathrm{~T}}$ \\
18 & 300 & 2.087 & $P=4.8876 e^{0.00185 \mathrm{~T}}$ \\
20 & 200 & 1.415 & $P=2.9459 e^{0.00124 \mathrm{~T}}$ \\
20 & 250 & 1.775 & $P=5.3170 e^{0.00039 \mathrm{~T}}$ \\
20 & 300 & 2.056 & $P=6.0304 e^{0.00096 \mathrm{~T}}$ \\
\hline
\end{tabular}

content. ${ }^{1)}$ Although, the $\mathrm{Al}$ content is an important parameter affecting the temperature sensitivity values, there are some factors keeping the temperature sensitivity at a minimum. These are; narrow AP size distribution range, low $\mathrm{Al}$ content ( $\leq 20$ percent), small Al particle size. ${ }^{2)}$

In Roland's study, those factors were evaluated by varying the $\mathrm{Al}$ content as 16,18 and $20 \%$ in terms of coarse AP with the particle diameter of $127 \mu \mathrm{m}$, ultrafine AP having the particle diameter of $24 \mu \mathrm{m}$ and $\mathrm{Al}$ containing the particle diameter of $5 \mu \mathrm{m}$ for the temperature range of 219-347 K. In this study, while the Al content was used at the same amount as 16,18 and 20 percent, the temperature range varied among 231-323 K.

Even though, second and third factors were provided due to lower $\mathrm{Al}$ content and the usage of $5 \mu \mathrm{m} \mathrm{Al}$ particle size, the first factor limiting AP particle size distribution couldn't be achieved. As the particle sizes of coarse and fine AP approach each other, the ratio of one to the other decreases and the trend goes towards the lower temperature sensitivities. ${ }^{2)}$

Although, the ratio of coarse to fine AP particle size was 5-8 times higher than Roland's study, it was observed that lower temperature sensitivity values were determined. Temperature sensitivities were found by using three different propellant area ratios $(K)$ as 200, 250 and 300, while it was determined in Roland's study with only the $K$ value of 200 for three propellants as observed in Table 2.

Ln $P-T$ graphs of the three compositions having 16, 18 and $20 \% \mathrm{Al}$ for the $K$ value of 200, 250 and 300 are given in Figs. 1, 2 and 3 respectively. When the results attained from Figs. 1, 2 and 3 are compared, it can be said that the propellant containing 20\% $\mathrm{Al}$ and $65 \% \mathrm{AP}$ has the lowest temperature sensitivity value. The reason for this can be explained in terms of $\mathrm{Al}$ remaining without burning because of low AP content. Although, higher temperature sensitivity values were observed until $18 \% \mathrm{Al}$ content, poor combustion resulted in the lowest temperature sensitivity values at $20 \% \mathrm{Al}$.

Temperature sensitivity values of all compositions tested with three different $K$ values are lower than the maximum value given as $0.5 \% / \mathrm{K}$ in the literature. ${ }^{10)}$

At the end of the motor tests, two more relationships were 
Table 2. Comparison of temperature sensitivity values obtained from literature and this study.

\begin{tabular}{ccccc}
\hline & & $\begin{array}{c}\text { Roland's temperature } \\
\text { sensitivity values } \\
(219 \mathrm{~K}, 347 \mathrm{~K}) \\
(\% / \mathrm{K})\end{array}$ & $K$ & $\begin{array}{c}\text { Temperature } \\
\text { sensitivity values of } \\
\text { this study } \\
(231 \mathrm{~K}, 323 \mathrm{~K}) \\
(\% / \mathrm{K})\end{array}$ \\
\hline 16 & 200 & 0.123 & 200 & 0.1085 \\
& & & 250 & 0.1012 \\
& & & 300 & 0.0778 \\
\hline 18 & 200 & 0.109 & 200 & 0.0858 \\
& & & 250 & 0.1172 \\
& & & 300 & 0.1096 \\
\hline 20 & 200 & 0.081 & 200 & 0.0753 \\
& & & 250 & 0.0251 \\
& & & 300 & 0.0560 \\
\hline
\end{tabular}

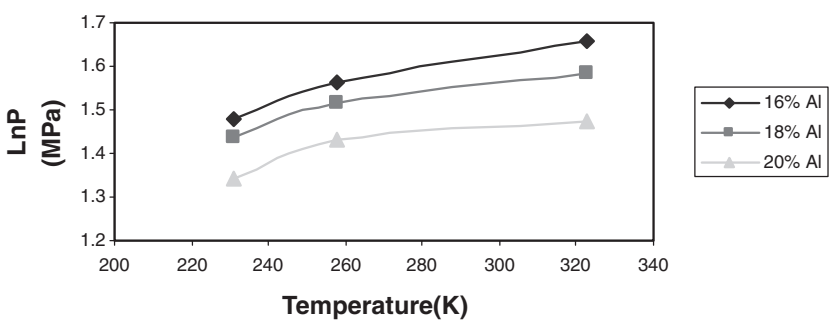

Fig. 1. Ln $P-T$ graph of propellants with the $K$ value of 200 .

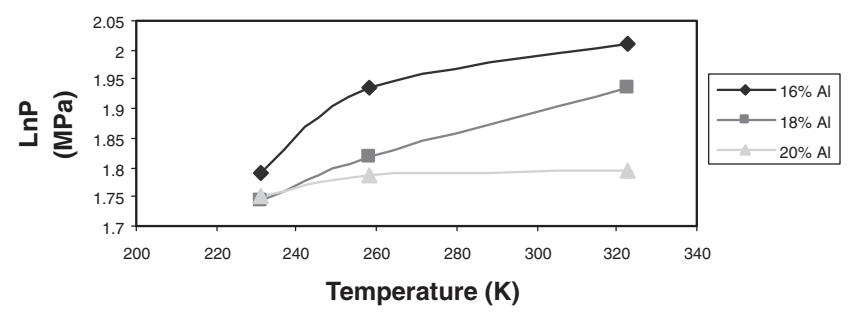

Fig. 2. Ln $P-T$ graph of propellants with the $K$ value of 250 .

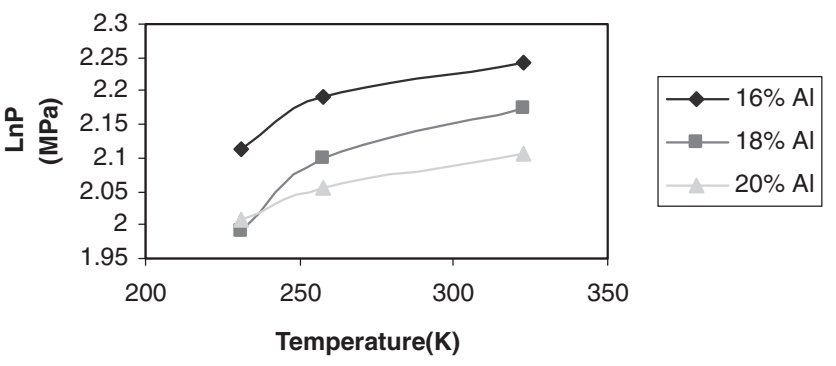

Fig. 3. Ln $P-T$ graph of propellants with the $K$ value of 300 .

also developed in addition to the first relationship. These are given below.

$$
\begin{gathered}
P=b K^{y} \\
r=c P^{n}
\end{gathered}
$$

Variation of coefficients in terms of $\mathrm{Al}$ content and temperature is observed in Table 3 . When the results attained from Table 3 were considered, pressure and burning rate increased with increasing $K$ value and temperature.
Table 3. Variation of burning rate and $P-K$ relationships of three propellant compositions with the coarse/fine AP ratio of 70/30 at three different temperatures.

\begin{tabular}{cccc}
$\begin{array}{c}\text { Aluminum } \\
(\%)\end{array}$ & $\begin{array}{c}\text { Temperature } \\
(\mathrm{K})\end{array}$ & $\begin{array}{c}r=c P^{n} \\
(\mathrm{~mm} / \mathrm{s})\end{array}$ & $\begin{array}{c}P=b K^{y} \\
(\mathrm{MPa})\end{array}$ \\
\hline 16 & 323 & $r=5.785 \mathrm{P}^{0.3620}$ & $P=0.00654 \mathrm{~K}^{1.2750}$ \\
16 & 258 & $r=5.122 \mathrm{P}^{0.3913}$ & $P=0.00130 \mathrm{~K}^{1.5501}$ \\
16 & 231 & $r=4.980 \mathrm{P}^{0.3733}$ & $P=0.00110 \mathrm{~K}^{1.5632}$ \\
18 & 323 & $r=4.283 \mathrm{P}^{0.4851}$ & $P=0.00529 \mathrm{~K}^{1.300}$ \\
18 & 258 & $r=5.010 \mathrm{P}^{0.3821}$ & $P=0.00233 \mathrm{~K}^{1.4293}$ \\
18 & 231 & $r=4.512 \mathrm{P}^{0.4168}$ & $P=0.00506 \mathrm{~K}^{1.2706}$ \\
20 & 323 & $r=4.847 \mathrm{P}^{0.4073}$ & $P=0.00050 \mathrm{~K}^{1.7000}$ \\
20 & 258 & $r=5.112 \mathrm{P}^{0.3547}$ & $P=0.00199 \mathrm{~K}^{1.4500}$ \\
20 & 231 & $r=5.195 \mathrm{P}^{0.3465}$ & $P=0.00315 \mathrm{~K}^{1.3625}$ \\
\hline
\end{tabular}

However, they decreased as $\mathrm{Al}$ content increased and AP content decreased.

\subsection{Mechanical properties}

The mechanical behavior of a propellant varies also with the temperature at which the measurement is made and with the rate of strain. A decrease in temperature increases the elastic modulus and the maximum tensile stress and decreases the elongation at maximum tensile stress. An increase in the strain rate has the same effect as a decrease in temperature. ${ }^{4)}$

As the mechanical properties of the propellants containing 16, 18 and $20 \% \mathrm{Al}$ were considered, experiments were performed at temperatures of 233, 248, 296, 308 and $323 \mathrm{~K}$. Variation of maximum tensile stress, elongation results at maximum tensile stress and elastic modulus values with temperature for three propellants is given in Figs. 4, 5 and 6.

It was observed that maximum tensile stress and elastic modulus values of the propellants containing 16, 18 and $20 \% \mathrm{Al}$ decreased, whereas, elongation at maximum tensile stress increased with increasing temperatures. This situation was appropriate for the literature ${ }^{4)}$ requiring elongation of a propellant with high stress.

When the mechanical properties of three compositions were evaluated, it was realized that the propellants having $20 \% \mathrm{Al}$ and $16 \% \mathrm{Al}$ had the highest values for maximum tensile stress and elastic modulus respectively. Maximum tensile stress increased with increasing the $\mathrm{Al}$ content in terms of temperature, while the lowest elastic modulus values were attained for the propellant including $18 \%$ Al. However, elongation at maximum tensile stress decreased as $\mathrm{Al}$ content increased with an increase in temperature, whereas, it was observed that elongation decreased above $308 \mathrm{~K}$ except for the propellant containing $20 \% \mathrm{Al}$. The reason for this may be explained in terms of better adhesion between HTPB and higher Al content. Since, the compositions having 16 and $18 \% \mathrm{Al}$ gave a decrease in elongation above $308 \mathrm{~K}$, while the propellant, including $20 \% \mathrm{Al}$, exhibited an increase in elongation.

\subsection{Performance values}

When the performance values containing burning time, 


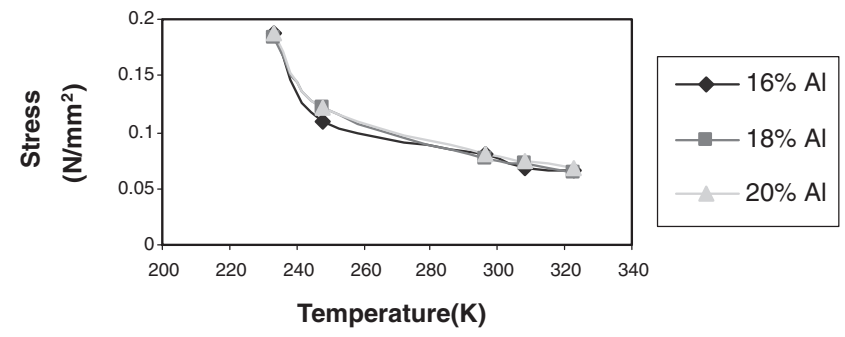

Fig. 4. Alteration of maximum tensile stress with the temperatures for three propellants.

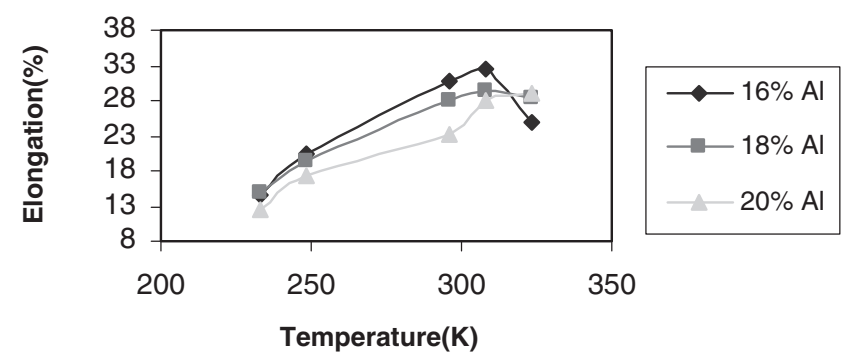

Fig. 5. Variation of elongation at maximum tensile stress with the temperatures for three propellants.

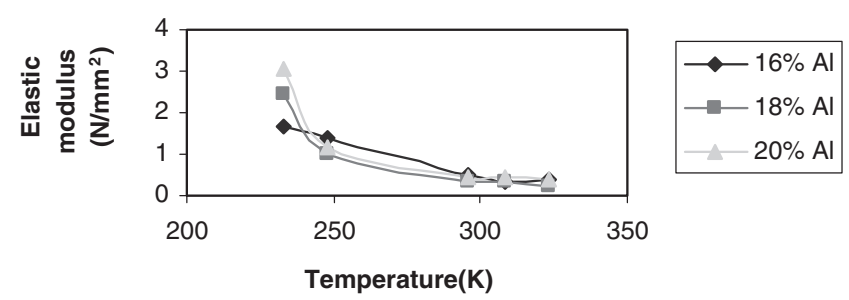

Fig. 6. Alteration of elastic modulus with the temperatures for three propellants.

burning pressure and characteristic velocity of the propellants including 16, 18 and $20 \% \mathrm{Al}$ were considered at the temperatures of $323 \mathrm{~K}, 258 \mathrm{~K}$ and $231 \mathrm{~K}$, the results obtained varied as followed from Eq. (2-5). Pressure increased and burning time decreased as temperature increased and pressure also increased with increasing $K$ values. Characteristic velocity decreased with a decrease in the pressure and temperature.

However, the variation of characteristic velocity with $K$ value for three propellant compositions at $323 \mathrm{~K}, 258 \mathrm{~K}$ and $231 \mathrm{~K}$ is also observed in Figs. 7, 8 and 9 respectively. When those figures were evaluated, it was found that characteristic velocity decreased with increasing the $K$ values for all propellants at three different temperatures. The reason why characteristic velocity decreases as $K$ values increase is that mass flow rate of the propellant increases because of an increase in the burning rate as a proportion with $P_{\mathrm{c}}{ }^{n}$ in terms of a rise in pressure. Since, pressure increases while increasing the $K$ value and decreasing the nozzle throat area, thus, burning rate increases as a proportion with $P_{\mathrm{c}}{ }^{n}$. In turn, mass flow rate of the propellant increases as a consequence of increasing the burning rate due to the effect of $\mathrm{Al}$ and $\mathrm{AP}$ content. Those variations give rise to reduction in characteristic velocity. ${ }^{11,12)}$

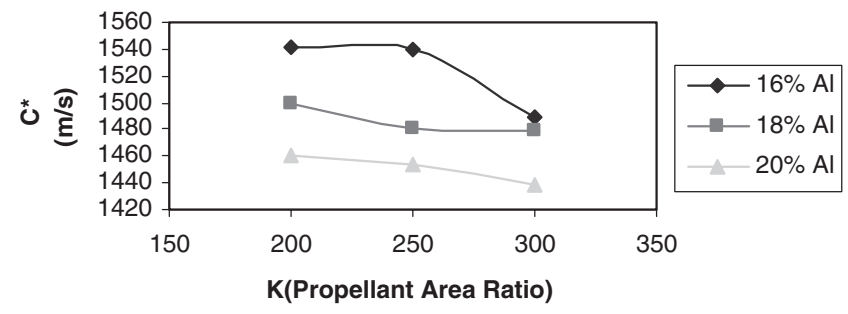

Fig. 7. Alteration of characteristic velocity with $K$ value for the three propellants at $323 \mathrm{~K}$.

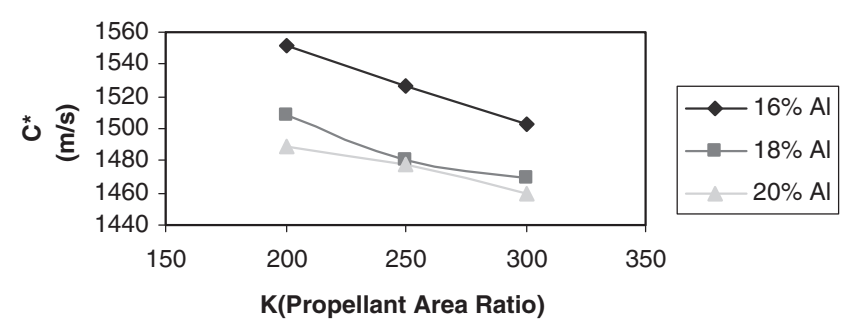

Fig. 8. Variation of characteristic velocity with $K$ value for the three propellants at $258 \mathrm{~K}$.

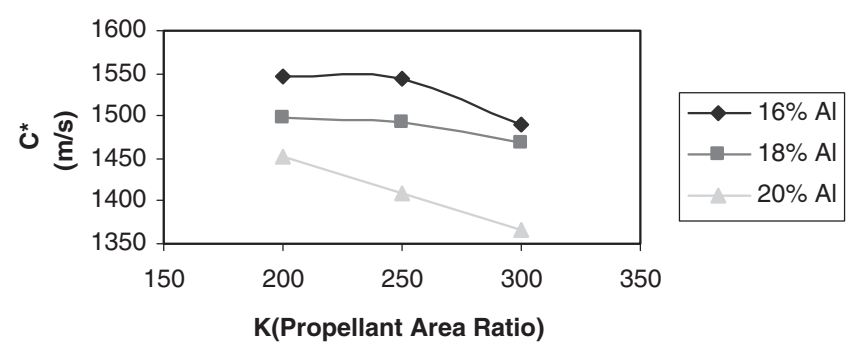

Fig. 9. Alteration of characteristic velocity with $K$ value for the three propellants at $231 \mathrm{~K}$.

While Figs. 7, 8 and 9 were considered, the highest characteristic velocity values were attained for the propellant including 16\% $\mathrm{Al}$ and $69 \% \mathrm{AP}$ at three different temperatures. Characteristic velocity decreases with increasing the $\mathrm{Al}$ and decreasing the AP content due to the formation of higher molecular weight combustion products. ${ }^{13)}$

The lowest characteristic velocity values were attained at $231 \mathrm{~K}$ for all propellants as well. The reason for this can be explained as a result of low temperature; since characteristic velocity decreases as temperature decreases owing to the decrease in pressure. ${ }^{14)}$ The variation of the standard deviations obtained in all characteristic velocity calculations for the three propellants and the three temperatures was found within $\pm 3 \%{ }^{15}$ ) This result showed the moisture was removed from the surroundings; therefore, the solubility of $\mathrm{AP}$ in the moisture was prevented.

\section{Conclusions}

The propellant including 20\% $\mathrm{Al}$ and $65 \% \mathrm{AP}$ has the lowest temperature sensitivity value among the three compositions. However, the results obtained from the three compositions are minimum temperature sensitivity values and 
they don't exceed $0.5 \% / \mathrm{K}$ which is accepted as the maximum value.

The highest pressure and burning rate was attained with the $K$ value of 300 at $323 \mathrm{~K}$ for the propellant including $16 \% \mathrm{Al}$ and $69 \% \mathrm{AP}$.

The propellants containing 20\% $\mathrm{Al}$ and $16 \% \mathrm{Al}$ have the highest tensile stress and elongation values respectively.

Evaluation of the performance results shows that combustion pressure increases and burning time decreases as temperature increases. On the other hand, combustion pressure increases with an increase in the $K$ value. Characteristic velocity decreases with an increase in the $K$ value, $\mathrm{Al}$ content and a decrease in the AP content, temperature and pressure. The highest characteristic velocity values were obtained by the propellant having 16\% $\mathrm{Al}$ and $69 \% \mathrm{AP}$.

\section{References}

1) Patil, M. S. and Singh, H.: Ballistic and Mechanical Properties of HTPB Based Composite Propellants, J. Hazardous Materials, 19 (1988), pp. 271-278.

2) Roland, M. M.: Factors Affecting $K$ in HTPB Formulations, John Wiley and Sons, Inc., New York, 1983, pp. 99-105.

3) Zucrow, M. J.: Aircraft and Missile Propulsion, Vol. 2, Chp. 10, John Wiley and Sons Inc., New York, 1958.

4) Klager, K. and Wrightson, J. M.: Recent Advances in Solid Propellant Binder Chemistry, Warren, F.A. (ed.), Mechanics and Chemistry of Solid Propellants, Pergamon Press, New York, 1970, pp. 47-74.

5) Smith, T. L.: Elastomeric Binder and Mechanical Property Require- ments, Ind. Eng. Chem., 52 (1960), p. 776.

6) Chan, M. L. and Turner, A. D.: US Patent \# 6863751, Minimum Signature Propellant, The United States of America as represented by the Secretary of the Navy, Washington, DC, 2003.

7) Kit, B. and Evered, D. C.: Rocket Propellant Handbook, first printing, The Macmillan Company, New York, 1960, pp. 3-33.

8) MIL-P-83405, Military Specification Propellant, Composite ADC109, American Military Standard, U.S. Government Printing Office, 1973.

9) Özkar, S., Pekel, F. and Tüzün, F. N.: Effect of Aluminum Content and Particle Size on the Ballistic and Mechanical Properties of HTPB Based Composite Solid Propellants, Proceedings of 27th International Annual Conference of ICT, Karlsruhe, 1996, pp. 48/1-48/12.

10) Barrere, M., Jaumette, A., Veubeke, B. F. and Vandenkerckhove, J.: Rocket Propulsion, Elsevier Publishing Company, New York, 1960, pp. 190-228.

11) Sutton, G. P.: Rocket Propulsion Elements, sixth ed., John Wiley and Sons, Inc., New York, 1992.

12) Frolov, Yu. V., Zenin, A. A. and Yalkoviev, V. P.: Combustion of Ammonium Perchlorate in Layered Systems, Combust. Explosion and Shock Wawes, 5 (1972), pp. 373-376.

13) McCabe, W. L., Smith, J. C. and Harriott, P.: Unit Operations of Chemical Engineering, fourth ed., McGraw Hill Book Company, New York, 1985.

14) Kubota, N.: Survey of Rocket Propellants and Their Combustion Characteristics, Kuo, K. and Summerfield, M. (eds.), Fundamentals of Solid Propellant Combustion, Progress in Astronautics and Aeronautics, Vol. 90, AIAA, New York, 1984.

15) Smooke, M. D., Yetter, R. A., Parr, T. P. and Hanson-Parr, D. M.: Counter-Flow Diffusion Flames of Ammonium Perchlorate with Gaseous Fuels, Sixth International Microgravity Combustion Workshop, NASA Glenn Research Center, Cleveland, OH, CP-2001-210826, 2001, pp. $185-188$. 